\title{
Formation of Hierarchical 2D-Mos 2 Nanostructures over Carbon Fabric as Binder Free Electrode Material for Supercapacitor Applications
}

\author{
Selvaraj Shanthi ${ }^{1,2,3}$, Yasuhiro Hayakawa ${ }^{2}$, Suru Ponnusamy ${ }^{3}$, Hiroya Ikeda ${ }^{2 * \star}$ and Chellamuthu \\ Muthamizhchelvan ${ }^{3 *}$ \\ ${ }^{1}$ Graduate School of Science and Technology, Shizuoka University, Japan \\ ${ }^{2}$ Research Institute of Electronics, Shizuoka University, Japan \\ ${ }^{3}$ Department of Nanotechnology, SRM Institute of Science and Technology, India \\ shanthiselvaraj43@gmail.com, hayakawa.yasuhiro@shizuoka.ac.jp, suruponnus@gmail.com, \\ **ikeda.hiroya@shizuoka.ac.jp, *selvancm@gmail.com
}

\begin{abstract}
Carbon fabrics are the new generation promising electrode materials for super capacitors owing to their high electrical conductivity, high chemical stability and low thermal expansion. In this work, 2D-MoS nanostructures have been successfully deposited over the commercially available carbon fabric by hydrothermal approach, using silicontungstic acid as an additive. $\mathrm{MoS}_{2}$ nanostructures - carbon fabric was broadly characterized using XRD, FESEM and Raman Spectroscopy. XRD patterns indicated that the fabricated $\mathrm{MoS}_{2}$ nanoparticles can be indexed to hexagonal $(2 \mathrm{H})$ and rhombohedral (3R) phases. FESEM images revealed the formation of hierarchical 2D MoS 2 nanosheets arranged in a nanosphere like morphology over the carbon fabric. The electrochemical behavior of the $\mathrm{MoS}_{2}$ - carbon fabric and commercially available bare carbon fabric were studied using cyclic voltammetry analysis with different scan rates. The $\mathrm{MoS}_{2}$-carbon fabric exhibited an excellent electrochemical performance with a specific capacitance of $441 \mathrm{~F} / \mathrm{g}$ at a scan rate of $10 \mathrm{mV} / \mathrm{s}$. The good cyclic behavior with symmetric charging/discharging curves, constant specific capacitance for longer scan rates, suggesting that the $\mathrm{MoS}_{2}$ - carbon fabric electrode is a potential electrode material for high power applications.
\end{abstract}

Keywords: Carbon Fabrics (CF); 2D materials; $\mathrm{MoS}_{2}$ Nanosheets; binder-free electrode; Supercapacitors;

\section{Introduction}

Supercapacitors, also known as electrochemical capacitors, have been acknowledged for over fifty years and considered as one of the potential energy storage systems in addition to batteries, for various diverse applications such as portable electronics, surge power delivery devices for electric vehicles and digital calipers [1]. In recent years, tremendous efforts have been made to develop the electrode materials for supercapacitor applications to meet the energy requirements of daily life. The electrode materials for supercapacitor falls under three categories namely electrical double layer capacitors (EDLC), pseudocapacitors and hybrid capacitors [2-7]. In EDLC, the electrical energy can be stored based on the following phenomena of either charge accumulation at the electrode and electrolyte interface, e.g., carbon-based materials and graphene, which has high surface area, excellent electrical conductivity. In pseudocapacitors, the energy can be stored by reversible faradic redox reactions, e.g., transition metal oxides/hydroxides and conducting polymers, which has high specific capacitance and energy density. The hybrid capacitors are the combination of EDLC and pseudocapacitors.

Scientific community people are focusing on fabricating the high-performance supercapacitor with excellent electrochemical performance, flexible, binder free to their potential applications in flexible energy storage devices. To achieve the high-performance supercapacitors, hybrid electrode materials are highly recommended because of having excellent electrical conductivity, high surface area and high theoretical capacitance values. Recently, two-dimensional (2D) materials like transition metal dichalcogenide (TMD) such 
as $\mathrm{MoS}_{2}, \mathrm{WS}_{2}$, and $\mathrm{SnS}_{2}$ have gained attraction because of their unique electrical, optical and mechanical properties [8].

Among these, 2D-TMD materials $\mathrm{MoS}_{2}$ has attained special attention because of its earth abundant, large surface area and 2D structure preferring ion adsorption and transports but limited by its low intrinsic conductivity which leads to low energy density $[9,10]$. Additionally, while preparing the $\mathrm{MoS}_{2}$ based electrode materials, utilizing the binders and conductive agents decreases the energy density [11]. By considering the above facts, binder free fabrication of $\mathrm{MoS}_{2}$ nanostructures over the conductive substrates are quite appealing to develop the supercapacitors with excellent electrochemical performance. Because of inimitable properties like high flexibility, low cost, excellent electrical conductivity, good physical strength, carbon fabric (CF) is highly recommended to fabricate the binder-free electrodes for supercapacitor applications [12].

In this work, we report the simple hydrothermal synthesis of agglomerated 2D $\mathrm{MoS}_{2}$ nanosheets arranged over the commercially available $\mathrm{CF}$, like 2D MoS 2 nanospheres morphology. The electrochemical performances of the fabricated $\mathrm{MoS}_{2}-\mathrm{CF}$ was further investigated using electrochemical measurement system. It was found that the supercapacitor constructed with this type of binder-free electrode material exhibited a specific capacitance of $441 \mathrm{~F} / \mathrm{g}$ at the scan rate of $10 \mathrm{mV} / \mathrm{s}$, which offers a new generation two-dimensional electrode material for supercapacitors. For comparison, the electrochemical investigation of commercially available CF was also performed to check the influence of $2 \mathrm{D} \mathrm{MoS}_{2}$ for the supercapacitor applications.

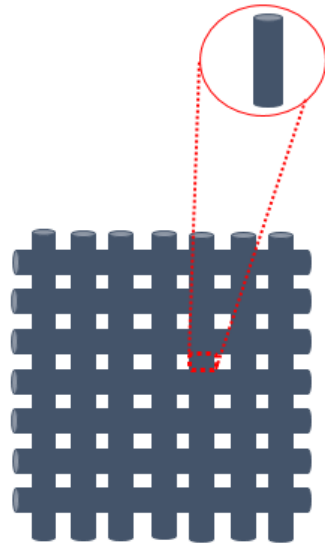

Carbon Fabric (CF)

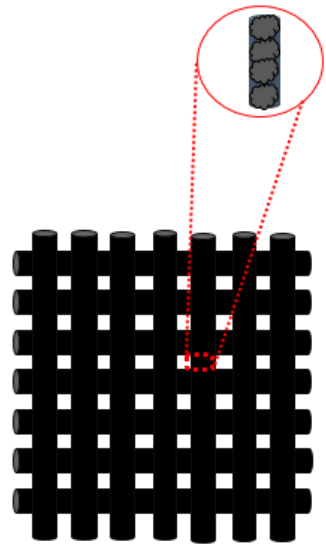

MoS2 - Carbon Fabric (CF)

Fig.1. Schematic representation- Fabrication of $\mathrm{MoS}_{2}$ nanostructures over CF, using hydrothermal synthesis.

\section{Materials and Methods}

All chemicals used were of analytical grade, purchased from Wako chemicals, Japan. Carbon fabric (CF) was purchased from sainergy fuel cell India, pvt limited. The commercially available bare CF and the fabricated binder free 2D-MoS 2 -CF electrodes were studied using X-ray diffractometer, XRD (RINT-2200, CuKa radiation, Rigaku) with $0.04{ }^{\circ} \mathrm{sec}-1 \mathrm{scan}$ rate in the $2 \theta$ range from $20^{\circ}$ to $80^{\circ}$, Raman scattering spectroscopy (NRS-7100, JASCO) with a laser excitation wavelength of $532 \mathrm{~nm}$ (spot size $1 \mu \mathrm{m}$ ) and field-emission scanning electron microscopy, FE-SEM (JSM 6335F, JEOL). Electrochemical characterizations were performed using CHI 600 series standard three electrode electrochemical Analyzer/Workstation. Here, the $\mathrm{MoS}_{2}-\mathrm{CF}$ as working electrode, $\mathrm{Ag} / \mathrm{AgCl}$ (saturated $\mathrm{KCl}$ ) as reference electrode and platinum wire as counter electrode were used along with $0.5 \mathrm{M}$ of $\mathrm{Con} . \mathrm{H}_{2} \mathrm{SO}_{4}$ as an electrolyte, during the electrochemical analysis. Electrochemical impedance spectroscopy (EIS) analysis were also carried out from $100 \mathrm{kHz}$ (Higher frequency) to $0.1 \mathrm{~Hz}$ (lower frequency) at open circuit potential with an AC perturbation voltage of about $5 \mathrm{mV}$.

Figure 1 shows the schematic representation of fabrication of $\mathrm{MoS}_{2}$ nanostructures over $\mathrm{CF}$, using hydrothermal synthesis. Prior to synthesis, commercially available CF was treated in ultrasonic bath with 
ethanol for about 1 hour, and then washed with distilled water to remove the impurities, which was used as a conductive template for the growth of $\mathrm{MoS}_{2}$ nanostructures. $0.5 \mathrm{~g}$ of $\mathrm{Na}_{2} \mathrm{MoO}_{4} .2 \mathrm{H}_{2} \mathrm{O}$ and $0.7 \mathrm{~g}$ of $\mathrm{CH}_{3} \mathrm{CSNH}_{2}$ were dissolved in $50 \mathrm{ml}$ of distilled water. Then, $8.0 \mathrm{~g}$ of sillicontungstic acid was added into the reaction mixture solution under vigorous stirring. The mixture solution along with the CF was then transferred into a $100 \mathrm{~mL}$ Teflon-lined stainless-steel autoclave apparatus and kept at $200{ }^{\circ} \mathrm{C}$ for $24 \mathrm{hrs}$. After cooling to room temperature, the fabricated binder free $\mathrm{MoS}_{2}-\mathrm{CF}$ electrode was taken from the autoclave and washed with absolute ethanol and distilled water for several times and annealing at $300^{\circ} \mathrm{C}$ for $5 \mathrm{hrs}$.

The capacitance values were calculated from CV data according to the following equation,

$$
C_{\text {device }}=\frac{1}{v\left(V_{f}-V_{i}\right)} \int_{V i}^{V f} I(V) d V \ldots \ldots \ldots \ldots \ldots \ldots \ldots \ldots . . .(\text { Equation 1) }
$$

where $v$ is the scan rate, $V_{f}$ and $V_{i}$ are integrated potential limits of voltammetric curve and $I(V)$ is the voltammetric discharge current. Specific capacitance of the electrodes can be calculated by the relation,

$$
C=\frac{c_{\text {device }}}{m} \ldots \ldots \ldots \ldots \ldots \ldots \ldots \ldots . . .(\text { Equation 2) }
$$

Where, $\mathrm{m}$ is the mass of the electrode material, respectively.

\section{Results and Discussion}

For the growth mechanism [13], it is clearly characterized that the chemical reaction of sodium molybdate with sillicontungstic acid tends to form molydosilic acid (from equation 3) under acid condition whose typical form is $\mathrm{H}_{4} \mathrm{SiMo}_{12} \mathrm{O}_{40}$. On the other hand, the $\mathrm{Mo}(\mathrm{VI})$ can be easily reduced with some reductants such as $\mathrm{H}_{2} \mathrm{~S}$ in the solution $[14,15]$. During the hydrothermal process, the reductant is $\mathrm{H}_{2} \mathrm{~S}$ which was provided by $\mathrm{CS}\left(\mathrm{NH}_{2}\right)_{2}$, from equation 4) because $\mathrm{CS}\left(\mathrm{NH}_{2}\right)_{2}$ can be easily decomposed in solution [16]. Thus, the oxidation-reduction reactions held during the hydrothermal process should be responsible for the formation of agglomerated $\mathrm{MoS}_{2}$ nanosheets in to $\mathrm{MoS}_{2}$ nanospheres like morphology over the CF (from equation 5). The intermediate product $\mathrm{H}_{4} \mathrm{SiMo}_{12} \mathrm{O}_{40}$ could serve as a self-sacrificial template for the subsequent growth of $\mathrm{MoS}_{2}$ nanospheres like morphology. Based on the above analysis, the reaction mechanism for the formation of $\mathrm{MoS}_{2}$ nanostructures can be expressed as follows:

$$
\begin{aligned}
& \mathrm{Na}_{2} \mathrm{MoO}_{4}+\mathrm{H}_{4} \mathrm{O}_{40} \mathrm{SiW}_{12} \rightarrow \mathrm{H}_{4} \mathrm{SiMo}_{12} \mathrm{O}_{40}+12 \mathrm{Na}_{2} \mathrm{WO}_{4} \ldots \ldots \ldots . . . . \text { (Equation 3) } \\
& \mathrm{CH}_{3} \mathrm{CSNH}_{2}+2 \mathrm{H}_{2} \mathrm{O} \rightarrow \mathrm{H} 2 \mathrm{~S}+\mathrm{CH}_{3} \mathrm{COOH}+\mathrm{NH}_{3} \ldots \ldots \ldots . . . \text { (Equation 4) } \\
& \mathrm{H}_{4} \mathrm{SiMo}_{12} \mathrm{O}_{40}+\mathrm{H}_{2} \mathrm{~S} \rightarrow 12 \mathrm{MoS}_{2}+\mathrm{H}_{2} \mathrm{SiO}_{3}+3 \mathrm{H}_{2} \mathrm{SO}_{4}+25 \mathrm{H}_{2} \mathrm{O} \ldots \ldots \ldots . . . \text { (Equation 5) }
\end{aligned}
$$

Figure 2 represents the XRD analysis of (a) commercially available CF and (b) the fabricated $\mathrm{MoS}_{2}-\mathrm{CF}$. The diffraction crystal planes (002) and (100), corresponded to the hexagonal primitive structure of carbon (JCPDS 89-8487) [17]. The diffraction peaks correspond to (002), (100), (101), (103), and (105) reflections, signified the nanostructured $2 \mathrm{H}-\mathrm{MoS}_{2}$ (JCPDS 37-1492) [18]. And the diffraction peaks which correspond to (004), (101) indicated the nanostructured 3R-MoS 2 (JCPDS 17-0744) [19]. 


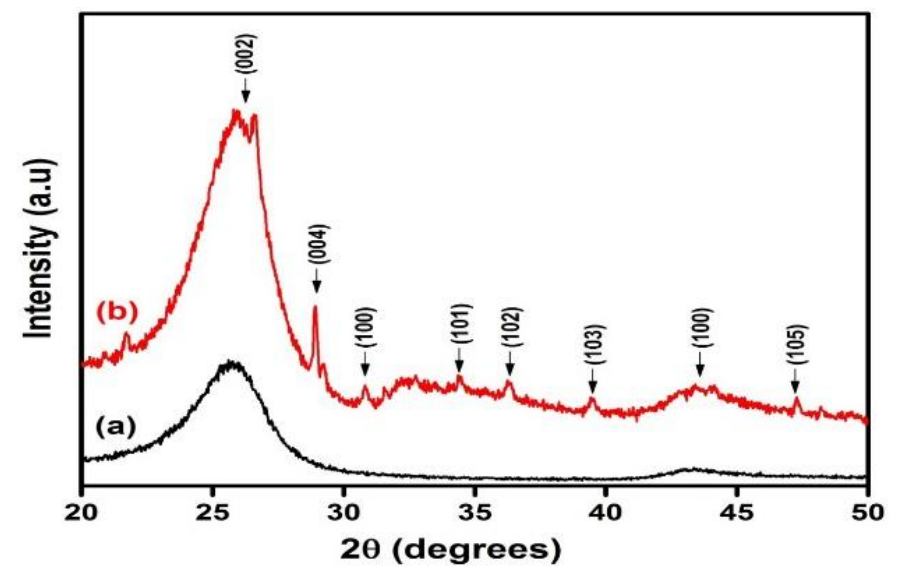

Fig. 2. XRD Analysis of (a) CF and (b) $\mathrm{MoS}_{2}-\mathrm{CF}$.
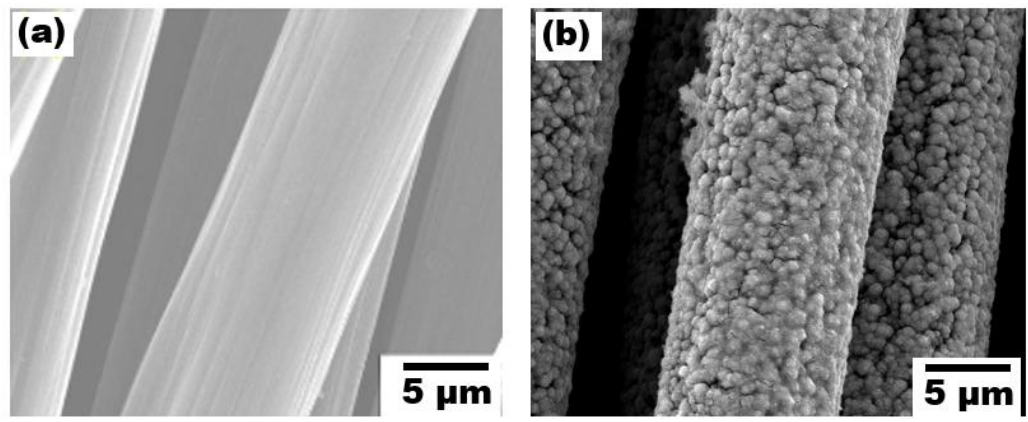

Fig.3. FESEM analysis of (a) CF and (b) $\mathrm{MoS}_{2}-\mathrm{CF}$

Figure 3 shows the typical FESEM analysis of (a) CF and (b) $\mathrm{MoS}_{2}-$ CF. From Figure 3(a), it is clearly seen that the carbon fabrics are compactly packed with random orientation in order to form a macroporous open structure [20,21]. This kind of porous material provide better accessibility to the electrolyte. Hierarchical 2D $\mathrm{MoS}_{2}$ nanosheets were agglomerated in to $\mathrm{MoS}_{2}$ nanosphere like morphology with uniform distribution over the $\mathrm{CF}$, as shown in Figure 3(b). Thus, this type of 2D- $\mathrm{MoS}_{2}$ nanostructures over the CF facilitates an excellent electrochemical performance for high power applications, because of its high surface area.

Figure 4 shows the Raman spectroscopy (a) CF and (b) $\mathrm{MoS}_{2}-\mathrm{CF}$. From the Raman spectra of Figure 4(a) and 4(b), the two high intensity peaks obtained at $1349 \mathrm{~cm}^{-1}$ and $1586 \mathrm{~cm}^{-1}$, depicted the $D$ and $G$ bands of CF [22]. Hence, the calculated $I_{D} / I_{G}$ ratio for $M_{0} S_{2}-C F$ and $C F$ are 1.2 and 1.14 respectively. From Figure 4(b), the obtained Raman modes (in-plane optical vibration of Mo and $S$ atoms) $E_{2 g}^{1}\left(403 \mathrm{~cm}^{-1}\right)$ and $\mathrm{E}_{2 \mathrm{~g}}^{2}\left(377 \mathrm{~cm}^{-1}\right)$, with the frequency difference of $26 \mathrm{~cm}^{-1}$, represented the five-layer formation [23].

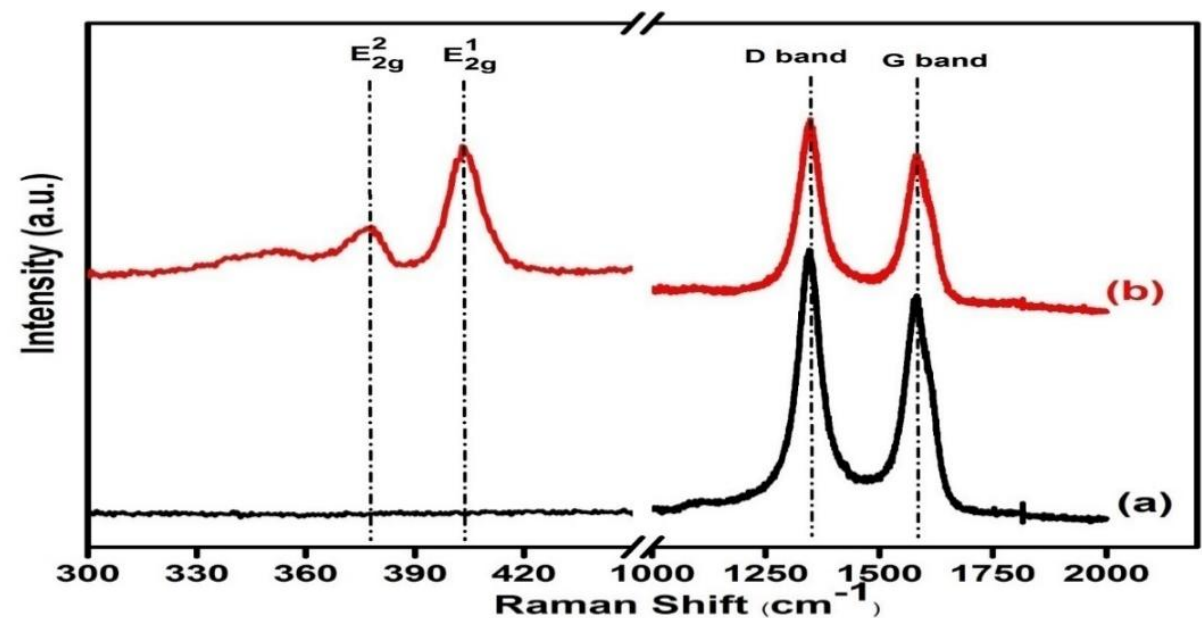


Fig. 4. Raman spectroscopy analysis of (a) CF and (b) $\mathrm{MoS}_{2}-\mathrm{CF}$.
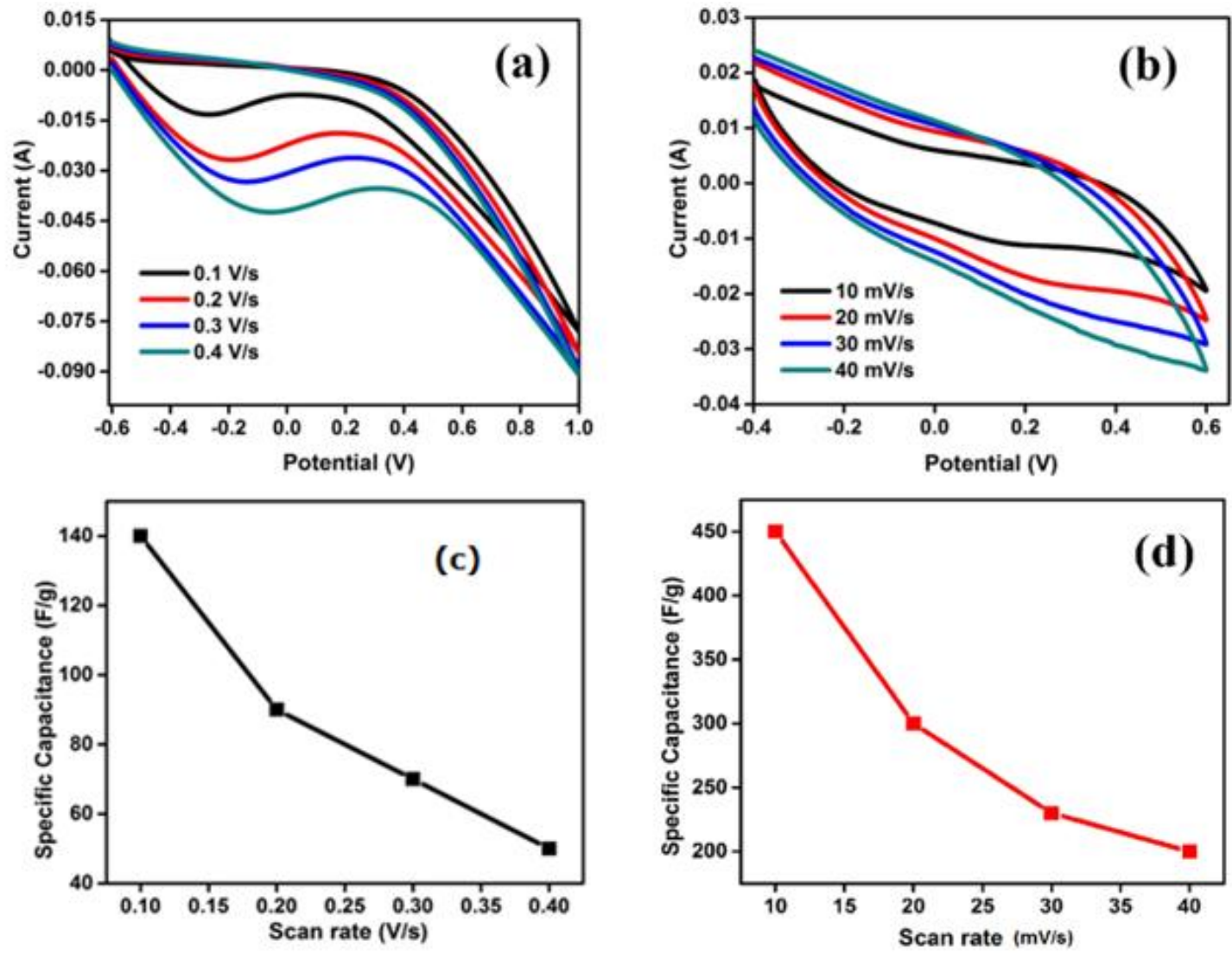

Fig. 5. Cyclic Voltammertry (CV) analysis of (a) CF and (b) $\mathrm{MoS}_{2}-\mathrm{CF}$. Relation between Specific capacitance and Scan rate.

The cyclic voltammetry (CV) analysis of CF and $\mathrm{MoS}_{2}-\mathrm{CF}$ were shown in Figure 5(a) and (b). The CV analysis of CF exhibited an exceptional performance with asymmetric curve pattern of charging/discharging electrochemical behavior of specific capacitance value as $145 \mathrm{~F} / \mathrm{g}$ at the scan rate of $0.1 \mathrm{~V} / \mathrm{s}$, as shown in Figure $5(a)$. From Figure 5(b), it is clearly seen that the fabricated binder free $\mathrm{MoS}_{2}-\mathrm{CF}$ exhibited an enhanced electrochemical performance with almost rectangular pattern of cyclic loop with maximum specific capacitance value as $441 \mathrm{~F} / \mathrm{g}$ at the scan rate of $10 \mathrm{mV} / \mathrm{s}$. The enhancement in capacitance is due to the increased surface area of $\mathrm{MoS}_{2}-\mathrm{CF}$. This behavior of symmetric in charging and discharging cycles helps to use it in high power applications. This linear and symmetric curve exposed the good capacitive electrochemical behavior of $\mathrm{MoS}_{2}-\mathrm{CF}$. Variations of specific capacitance for different scan rates were represented in Figure 5(c) and (d). It revealed that constant value of specific capacitance can be achieved at higher scan rates, which is the potential significance of the electrode materials. 


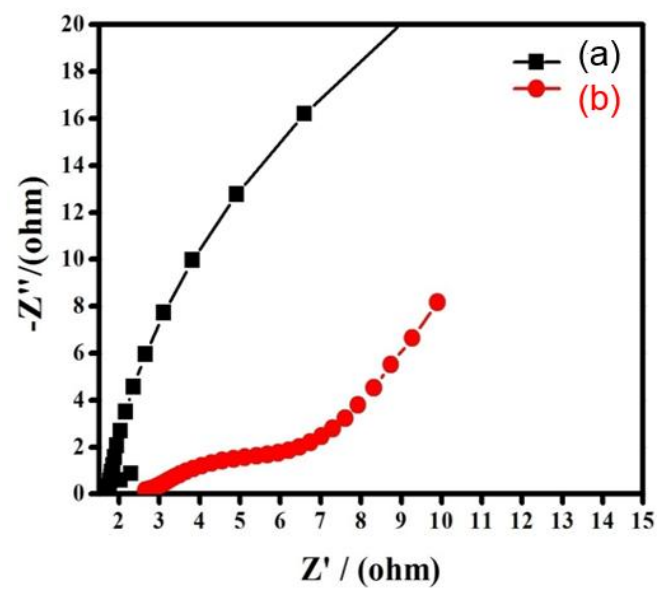

Fig.6. Electrochemical impedance Spectroscopy(EIS) analysis (a) CF and (b) $\mathrm{MoS}_{2}-\mathrm{CF}$.

Figure 6 represents the electrochemical impedance spectra(EIS) of CF and $\mathrm{MoS}_{2}-\mathrm{CF}$. Figure 6(a) depicts the impedance spectra of CF. From Figure 6(b), the impedance plot of $\mathrm{MoS}_{2}$-CF shows a quadrant circle in the higher frequency region and a $45^{\circ}$ capacitive slope in the lower frequency region. The higher frequency intercept of the quadrant circle on the real axis of the impedance plot is the combination of the resistance of the electrolyte, the intrinsic resistance of the active material of $\mathrm{MoS}_{2}-\mathrm{CF}$ and the contact resistance between the active material $\mathrm{MoS}_{2}$ and the current collector CF.

\section{Conclusions}

Formation of hierarchical 2D MoS 2 nanostructures over the carbon fabric (CF) was demonstrated using a simple hydrothermal route. FE-SEM analysis exposed the formation of $\mathrm{MoS}_{2}$ nanospheres like morphology over the CF with homogeneity. FE-SEM results are in good agreement with XRD and Raman results. Electrochemical analysis revealed the excellent electrochemical performance of $\mathrm{MoS}_{2}$ - CF electrode with the specific capacitance value of $441 \mathrm{~F} / \mathrm{g}$ at a scan rate of $10 \mathrm{mV} / \mathrm{s}$, suggesting that it is a potential electrode material for high power applications.

\section{Conflicts of Interest}

The authors declare no conflicts of interest.

\section{Acknowledgments}

This work was financially supported in part by a JST CREST Grant Number JPMJCR15Q7, Japan.

\section{References}

[1] C. D. Lokhande, D. P. Dubal, and O. S. Joo, Current Appl. Phys., 11, (2011), 255.

[2] G. Wang, L. Zhang, and J. Zhang, Chem. Soc. Rev., 41, (2012), 797.

[3] M. Salanne, B. Rotenberg, K. Naoi, K. Kaneko, P. L. Taberna, C.P. Grey, B. Dunn, and P. Simon, Nat. Energy, 1, (2016) 16070.

[4] Y.A. Kumar, S.S. Rao, D. Punnoose, C.V. Tulasivarma, C.V. Gopi, K. Prabakar, and H. J. Kim, Royal Soc. open sci., 4, (2017) 170427.

[5] J. Zhang, H. Guan, Y. Liu, Y. Zhao, and B. Zhang, Electrochimica Acta, 258, (2017) 182. 
[6] Y. Tao, L. Ruiyi, Z. Lin, M. Chenyang, and L. Zaijun, Electrochimica Acta, 176, (2015) 1153.

[7] J. Jiang, Y. Zhang, P. Nie, G. Xu, M. Shi, J. Wang, Y. Wu, R. Fu, H. Dou, and X. Zhang, Adv. Sustainable Sys., 2, (2018), 1700110.

[8] S. A. Han, R. Bhatia and S. W. Kim, Nano Convergence, 2, (2015),17.

[9] J. Huang, D. Hou, Y. Zhou, W. Zhou, G. Li, Z. Tang, L. Li, and S. Chen, J. Mater. Chem. A, 3, (2015), 22886.

[10] F. N. I. Sari, and J. M Ting, Sci. Rep., 7, (2017), 5999.

[11] N. Chen, C. Han, R. Shi, L. Xu, H. Li, Y. Liu, and B. Li, Electrochimica Acta, 283, (2018), 36.

[12] N. Zhang, S. Gan, T. Wu, W. Ma, D. Han, and L. Niu, ACS Appl. Mat. \& Inter., 7, (2015), 12193.

[13]. H. Lin, X. Chen, H. Li, M. Yang, and Y. Qi, Mater. Lett., 64, (2010), 1748.

[14] W. Huang, Z. Xu, R. Liu, X. Ye, and Y. Zheng, Mater. Res. Bull., 43, (2008), 2799.

[15] L. Ma, L. M. Xu, X. Y. Xu, Y. L. Luo, and W. X. Chen, Materials Letters, 63, (2009), 2022.

[16]. M. M. Mdleleni, T. Hyeon, and K. S. Suslick, J. Am. Chem. Soc., 120, (1998), 6189.

[17]. Y. W. Lee, G. H. An, S. Lee, J. Hong, B. S. Kim, J. Lee, D. H Kwak, H.J. Ahn, W. Huh, S. N. Cha, K. W. Park, J. I. Sohn, and J. M. Kim, Catalys. Sci. \& Tech., 6, (2016), 2085.

[18]. Z. Wang, L. Ma, W. Chen, G. Huang, D. Chen, L. Wang, and J. Y. Lee, RSC Adv., 3, (2013), 21675.

[19]. N. Saha, A. Sarkar, A. B. Ghosh, A. K. Dutta, G. R. Bhadu, P. Paul, and B. Adhikary. RSC Adv., 5, (2015), 88848.

[20]. S. Huang and J. Shi, Ind. Eng. Chem. Res., 53 (2014), 4888.

[21]. Y. B. Yin, J. J. Xu, and Q. C. Liu, Advanced Materials, 28, (2016), 7494.

[22]. M. Govindasamy, S. Shanthi, E. Elaiyappillai, S. F. Wang, P. M. Johnson, H. Ikeda, Y. Hayakawa, S. Ponnusamy, C. Muthamizhchelvan, Electrochimica Acta, 293, (2019), 328.

[23]. G. Plechinger, S. Heydrich, J. Eroms, D. Weiss, C. Schuller, and T. Korn, Appl. Phys. Lett., 101, (2012) 101906. 